\title{
Influence of 24-Epibrassinolide on Physiological Characteristics of Tomato Seedlings Infested with Root-knot Nematode Meloidogyne incognita (Kofoid \& White, 1919) Chitwood, 1949 (Tylenchida: Meloidogynidae)
}

\author{
Çiğdem GÖZEL ${ }^{\mathrm{a}^{*}}$ (D), Zeliha GÖKBAYRAK ${ }^{\mathrm{b}}$

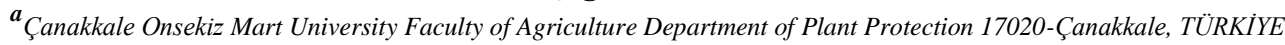

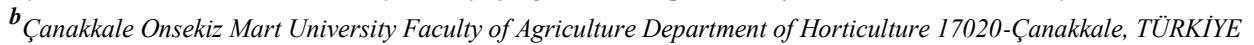

\section{ARTICLE INFO}

Research Article

Corresponding Author: Çiğdem GÖZEL, E-mail: cigdemgunes@comu.edu.tr

Received: 21 June 2021 / Revised: 19 November 2021 / Accepted: 19 November 2021 / Online: 15 October 2022

Cite this article

GÖZEL Ç, GÖKBAYRAK Z (2022). Influence of 24-Epibrassinolide on Physiological Characteristics of Tomato Seedlings Infested with Root-knot Nematode Meloidogyne incognita (Kofoid \& White, 1919) Chitwood, 1949 (Tylenchida: Meloidogynidae). Journal of Agricultural Sciences (Tarim Bilimleri Dergisi), 28(4):650-655. DOI: 10.15832/ankutbd.955398

\section{ABSTRACT}

The aim of this research is to determine the physiological responses of tomato seedlings treated with 24-epibrassinolide (EBL), given via different methods such as immersion, irrigation, and foliar spray, followed by inoculation of root-knot nematode Meloidogyne incognita (Kofoid \& White 1919) Chitwood, 1949 (Tylenchida: Meloidogynidae). Physiological measurements (chlorophyll, flavonols, nitrogen balance index, and anthocyanins) were carried out non-destructively with a portable chlorophyll meter at the end of the 56th days post inoculation. Results showed that chlorophyll contents of the tomato leaves were affected by both the EBL applications and the methods. Chlorophyll contents were better protected with the irrigation method. Flavonols and nitrogen balance index were inversely related with the application method. Leaf anthocyanin index was affected just by the EBL applications. Depending on the physiological aspect under observation, the method (immersion against irrigation, for instance) might present a challenging status in terms of providing protection against root-knot nematode when tomato plants are treated with EBL.

Keywords: Brassinosteroids, Lycopersicon esculentum, Meloidogyne spp., Non-destructive sampling

\section{Introduction}

Responses of plants to stress factors are elucidated through assessment of changes in morphology, biochemistry, and genetics. Plant stress can be caused by abiotic factors, such as drought, salinity, or heat or by biotic ones such as diseases and herbivorous pests like viruses, bacteria, or nematodes (Jagodič et al. 2017; Voglar et al. 2019). Detrimental consequences occurring after a biotic or abiotic stress can be alleviated through the utilization of synthetic elicitors (Llorens et al. 2017), chemical compounds activating plant's reaction to sustain health and productivity (Ramírez-Godoy et al. 2018). Brassinosteroids are among these elicitors, and they have been proven by various research to stimulate antioxidant defense mechanism of a plant against numerous abiotic factors (Jan et al. 2018).

Most information about protective properties of brassinosteroids in plants under stress have been provided from studies evaluating abiotic factors such as salinity, drought, or heavy-metal accumulation in the soil. In these studies, it was reported that acquisition of resistance with brassinosteroid applications derive from protection of chlorophyll content, increase in photosynthetic rate and stimulation of antioxidative system (Fariduddin et al. 2013; Yang et al. 2019; Santos de Fonseca et al. 2020). On the other hand, research pertaining to the effects of brassinosteroids in protecting plants against pathogen attacks have been quite limited. They were found to mitigate fungus-related deleterious influences in cotton (Bibi et al. 2017), cucumber (Ding et al. 2009) and barley (Ali et al. 2013).

Increases in resistance after brassinosteroid application against viruses have also been shown by Ali et al. (2014) in Hordeum vulgare, and by Zhang et al. (2015) in Arabidopsis thaliana. In recent years, responses against root-knot nematode damage in plants have also been carried out and positive results have been reported by Jasrotia \& Ohri (2014; 2017), Kaur et al. (2013; 2014), Song et al. (2017) and Gözel (2021) against Meloidogyne incognita (Kofoid \& White 1919) Chitwood 1949 (Tylenchida: Meloidogynidae). 
Early detection of stress symptoms in plants presents an invaluable tool to manage and abate them before any reduction in yield and quality appears and causes an income loss. Non-destructive and in-field measurement via technological tools, thermographic or optical, have made it possible. Among these tools, leaf-clip chlorophyll-meters use chlorophyll fluorescence screening method (Agati et al. 2016), and estimate chlorophyll, flavonoids, and anthocyanins. These optical sensors have been shown to be superior to lab-based and destructive leaf chlorophyll measurement (Dong et al. 2019).

As opposed to abundant research on effects of brassinosteroids on plant growth and development as well as on response to abiotic stress, information about their role against biotic stress, specifically plant parasitic nematodes, are quite limited. Thus, aim of this study was to non-destructively evaluate whether exogenously applied 24-epibrassinolide to roots or leaves can induce protective effects on physiological aspects (chlorophyll, flavonols or antioxidants) of tomato seedlings inoculated with $M$. incognita.

\section{Material and Methods}

\subsection{Plant material and nematode inoculum}

3-4 leaved seedlings of tomato (Lycopersicon esculentum Mill.) cv. Heinz 2274 were obtained from a commercial nursery. These seedlings used in a study conducted at Department of Plant Protection, Faculty of Agriculture, University of Çanakkale Onsekiz Mart, Çanakkale in 2020. Second-stage juveniles (J2s) of Meloidogyne incognita after reproduction from a single egg mass on a cucumber plant were inoculated at the dose of 1000 per plant.

\subsection{4-epibrassinolide application and nematode inoculation}

E-1641 EBL (Sigma Aldrich) was used after dilution in ethanol absolute, and working solutions of 1, 5 and $10 \mu \mathrm{M}$ were prepared. Experimental design was shown in Table 1. Repetitive applications of irrigation and spraying were done at transplanting and on the following $7^{\text {th }}$ and $14^{\text {th }}$ day.

Table 1- Experimental design of the study

\begin{tabular}{cccc}
\hline \multirow{2}{*}{ Methods } & $E B L$ & Nematode inoculation & Application times $(x)$ \\
\hline \multirow{3}{*}{ Immersion } & $0(\mathrm{DW})$ & - & 1 \\
$(10$ min. $)$ & $0(\mathrm{DW}+\mathrm{J} 2 \mathrm{~s})$ & + & 1 \\
& 1 & $+/-$ & 1 \\
& 5 & $+/-$ & 1 \\
\hline \multirow{4}{*}{ Irrigation } & 10 & $+/-$ & 3 \\
& $0(\mathrm{DW})$ & - & 3 \\
& $0(\mathrm{DW}+\mathrm{J} 2 \mathrm{~s})$ & + & 3 \\
& 1 & $+/-$ & 3 \\
& 5 & $+/-$ & 3 \\
\hline \multirow{5}{*}{ Spraying } & 10 & $+/-$ & 3 \\
& $0(\mathrm{DW})$ & - & 3 \\
& $0(\mathrm{DW}+\mathrm{J} 2 \mathrm{~s})$ & + & 3 \\
1 & $+/-$ & 3 \\
& 5 & $+/-$ & 3 \\
\hline
\end{tabular}

\subsection{Growth conditions}

The pots (1.4-liter volume) into which the plants were transplanted contained 70:30 (v/v) sterilized sand and soil mixture (approx. $450 \mathrm{~g})$. Later the pots were placed in a growth chamber under the conditions of $26 \pm 1{ }^{\circ} \mathrm{C}$ and $18 / 6$ hours of photoperiod until the end of the experiment (56 days post inoculation).

\subsection{Data analysis}

At the end of the experiment synchronous readings using Dualex Scientific $+{ }^{\mathrm{TM}}$ were made on each side (abaxial and adaxial) of the third youngest leaf and a mean value was obtained. Measured indices were chlorophyll $\left(\mu \mathrm{g}\right.$ per $\left.\mathrm{cm}^{2}\right)$, relative absorbance units of flavonols ( 0 to 3 ) and anthocyanins ( 0 to 1.5 ), and the nitrogen balance index (NBI), determined by the relationship between chlorophyll and flavonols.

The experiment was arranged in a completely randomized design with three replications of one plant per pot. The data for chlorophyll, flavonols, anthocyanins and NBI were analyzed using ANOVA on Minitab ${ }^{\circledR}$ (v. 17.1.0 for Windows) statistics package program. Significant differences between the means were compared using Duncan’s multiple comparison test at $95 \%$ confidence level. 


\section{Results and Discussion}

Chlorophyll contents of the tomato leaves were interactively affected by both EBL applications and the methods they were given $(\mathrm{P}=0.001$, Figure 1). Best EBL applications in the immersion group protecting the chlorophyll contents were $5 \mu \mathrm{M}$ and $1 \mu \mathrm{M}+\mathrm{J} 2 \mathrm{~s}$, following the distilled water (DW). Irrigated plants had better contents in all the applications except for $5 \mu \mathrm{M}+\mathrm{J} 2 \mathrm{~s}, 10 \mu \mathrm{M} E B L+\mathrm{J} 2 \mathrm{~s}$ and DW+J2s. Foliar spraying was generally the least supporting in all treatments, except for $5 \mu \mathrm{M}$ EBL (Figure 1).

Effect of nematode inoculation on chlorophyll content was abated with $1 \mu \mathrm{M}$ EBL application given via irrigation. Increasing concentration did not provide a positive response in suppressing the nematode stress comparing to control groups (Figure 1). In general, irrigating the seedlings with $1 \mu \mathrm{M}$ EBL $+\mathbf{J} 2 \mathrm{~s}$ improved chlorophyll contents in the tomato leaves. Overall, irrigation was the best among the application methods at keeping chlorophyll at higher levels.

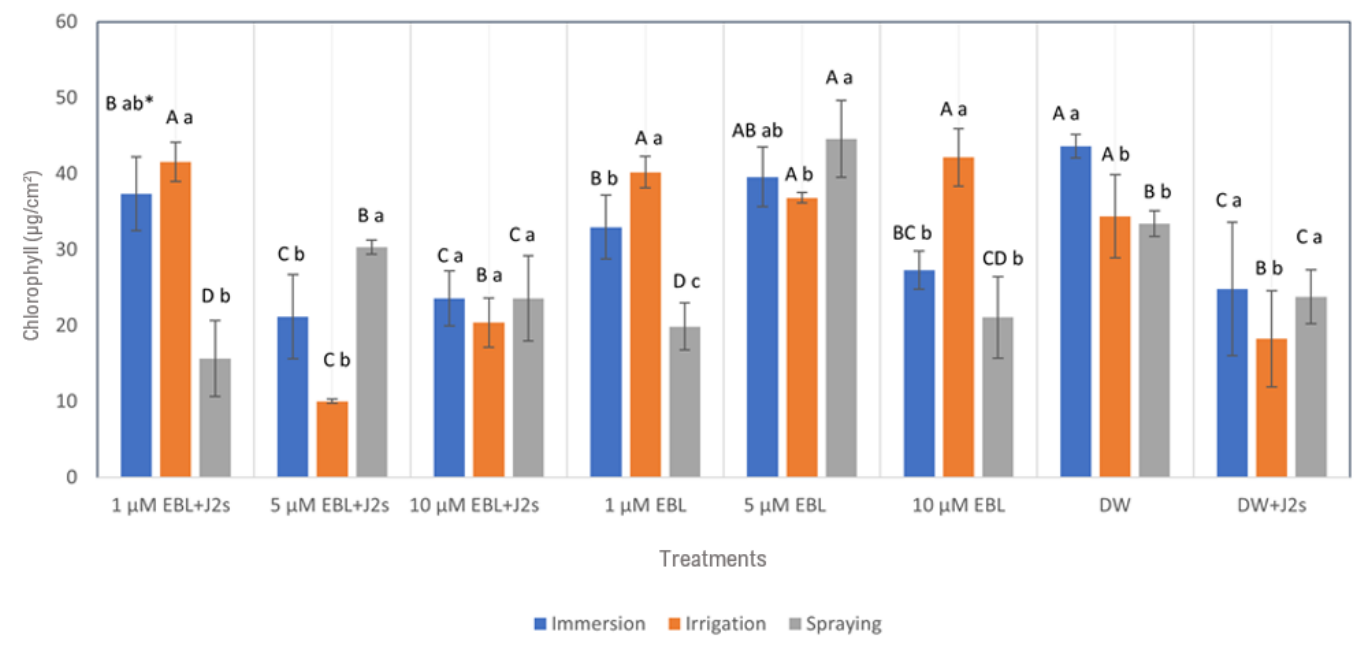

Figure 1- Effects of 24-epibrassinolide (EBL) on chlorophyll contents of tomato cv. Heinz 2274 plants given in three treatments (immersion, irrigation, and spraying) followed by Meloidogyne incognita inoculation at a dose of 1000

J2s. *Different capital letters denote significant differences in methods at the same concentration of EBL and different small letters indicate significance in the treatments of $E B L$ at the same methods. $\mathrm{P}=0.001$. Means \pm S.E.

NBI is an indicator of plant growth, using the relation between chlorophyll and flavanols contents (Figure 2). Although a significant effect of the applications was detected $(\mathrm{P}=0.019)$, a clear distinction was only seen between $\mathrm{DW}$ and $5 \mu \mathrm{M}$ EBL $+\mathrm{J} 2 \mathrm{~s}$. The NBI of the seedlings were in general supported by the EBL treatments in DW (nematode-free soil) more than DW+J2s, and as the concentration of EBL increased this effect was lessened. NBI was also under the influence of the methods (figure not shown, $\mathrm{P}=0.015$ ) and it was in the decreasing order of immersion, irrigation, and foliar spraying. Significant differences were only observed between immersion and foliar spraying.

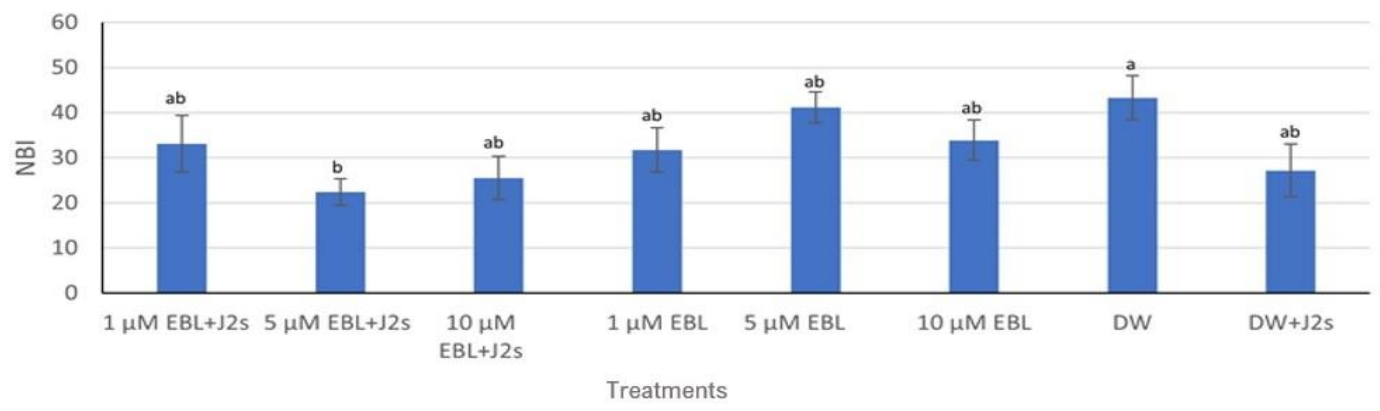

Figure 2- Effects of 24-epibrassinolide (EBL) on NBI (nitrogen balance index) of tomato cv. Heinz 2274 plants given in three treatments (immersion, irrigation, and foliar spraying) followed by Meloidogyne incognita inoculation at a dose of $1000 \mathrm{~J} 2 \mathrm{~s}$. * Different letters show significant differences at $\mathrm{P}<0.05$. Means \pm S.E.

Flavonols contents of the seedling significantly changed with the methods the EBL concentrations $(p=0.021)$ and distinct difference was only observed between the foliar spraying and the immersion methods (Figure 3 ). 


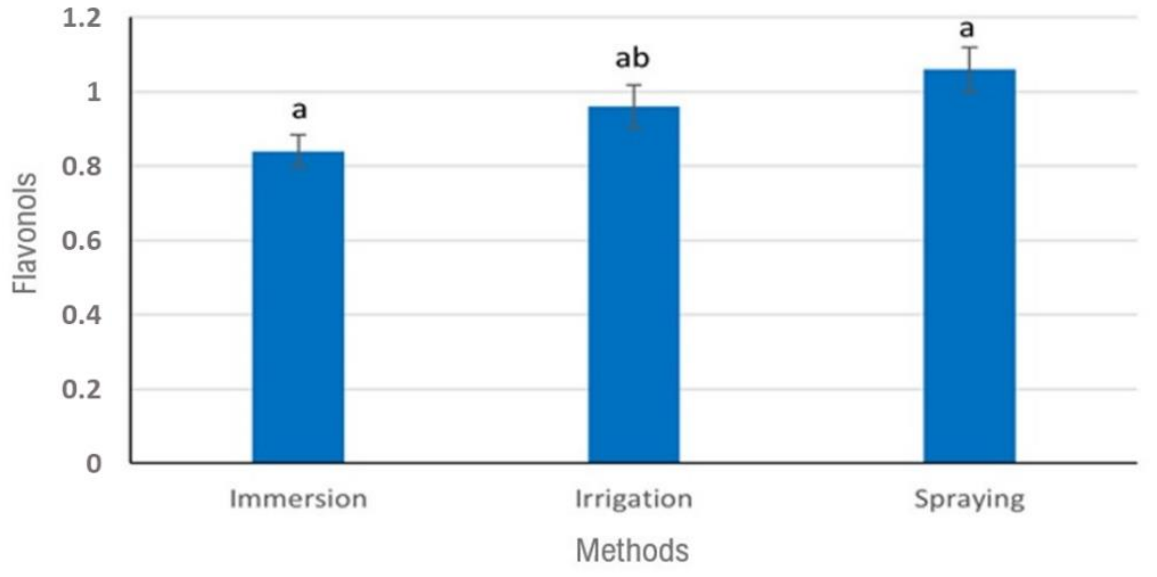

Figure 3- Effects of 24-epibrassinolide (EBL) on flavonols index (radiance absorbance unit, 0-3) of tomato cv. Heinz 2274 plants given in three treatments (immersion, irrigation, and foliar spraying) followed by Meloidogyne incognita inoculation at a dose of $1000 \mathrm{~J} 2 \mathrm{~s}$. *Different letters show significant differences at $\mathrm{P}<0.05$. Means \pm S.E.

Leaf anthocyanin contents of the seedlings at the end of the experiment was affected by the EBL applications $(\mathrm{P}=0.036$, Figure 4). The highest anthocyanin accumulation was observed in the DW $+\mathrm{J} 2 \mathrm{~s}$ application, indicating nematodes in the soil induced it as a response to the stress. However, the difference among the rest of the treatments was not clear enough to differentiate the effects of EBL. The application of $5 \mu \mathrm{M}$ EBL provided the lowest content of anthocyanins.

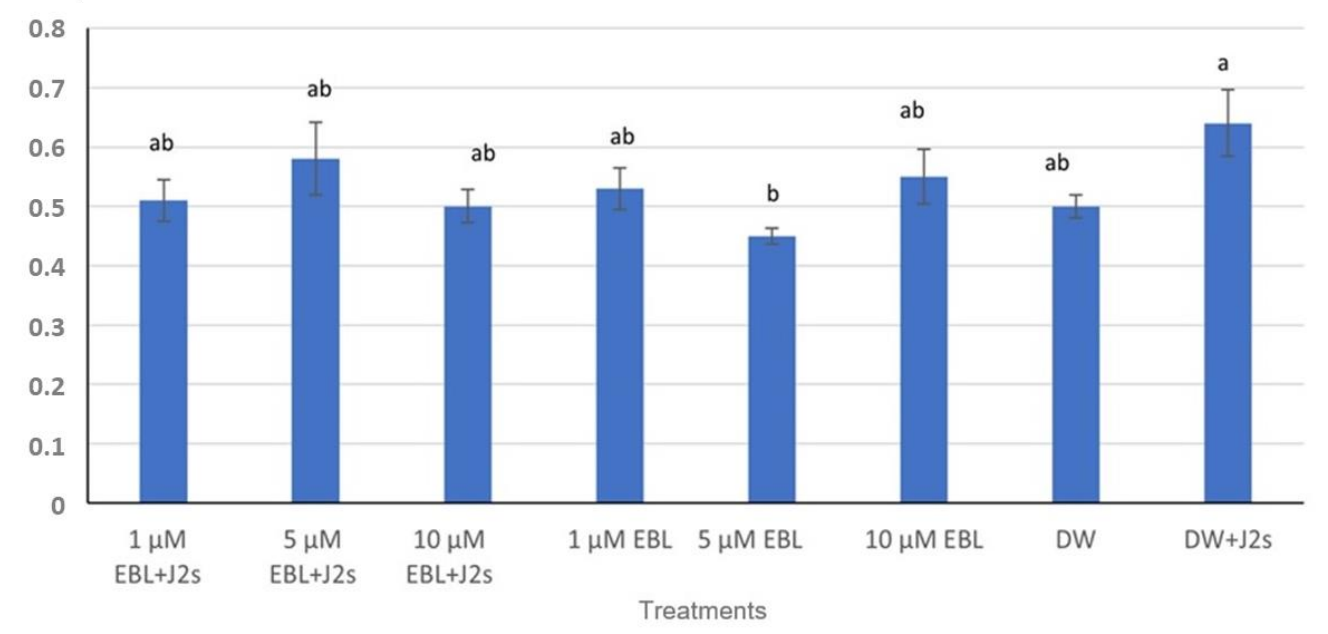

Figure 4- Effects of 24-epibrassinolide (EBL) on anthocyanins index (radiance absorbance unit, 0-1) of tomato cv. Heinz 2274 plants given in three treatments (immersion, irrigation, and foliar spraying) followed by Meloidogyne incognita inoculation at a dose of $\mathbf{1 0 0 0} \mathbf{J} 2 \mathrm{~s}$. *Different letters show significant differences at $\mathrm{P}<0.05$. Means $\pm \mathrm{S}$.E.

Root-knot nematodes induce plants to develop galls on their roots, damaging root structure and preventing water and nutrient uptake. Most of the assimilates produced in the plant is redirected from shoot to root to support nematode's growth and reproduction (Maleita et al. 2012). Since the study of Loveys \& Bird (1973), which showed that photosynthetic rate and chlorophyll content in the nematode infected plants decreased, several other reports (Melakeberhan et al. 1985; Gine et al. 2014; López-Gómez \& Verdejo-Lucas (2017) also supported this observation. In the current study, a great deal of reduction in chlorophyll was also observed in the DW plants with nematode infestation.

When plants were exposed to nematode infestation, applying $1 \mu \mathrm{M}$ EBL through immersion or irrigation resulted comparably closer chlorophyll contents to DW plants. As the concentration increased, the positive effect weakened and became negative. Similar results were obtained in rice plants to which brassinolide was given as foliar spraying (Nahar et al. 2013). Since low concentration $(0.1 \mu \mathrm{M})$ was successful in ameliorating the effects of $M$. graminicola, but higher concentrations $(1,5,10 \mu \mathrm{M})$ were not, they concluded that exogenous brassinolide created negative feedback on brassinosteroids biosynthesis. It has been also reported that brassinosteroids act as stimuli on chlorophyll through activation of chlorophyllase and Rubisco (Xia et al. 2009). 
NBI, the ratio of chlorophyll to flavonols, is an index proven to be a reliable indicator of plant N content (Cartelat et al. 2005; Padilla et al. 2014). The current study found that brassinosteroids application protected the $\mathrm{N}$ reserve of the nematode infested plants at the lowest concentration of EBL. Schlemmer et al. (2013) stated that chlorophyll is closely related to leaf N status. One possible reason for the root treatment to cause an increased $\mathrm{N}$ content might be the increased root activity and increased chlorophyll concentration in the leaves. This kind of relationship between NBI and the chlorophyll content can be seen in the response of DW plants, showing a decrease in the irrigated and sprayed plants. Changes depending on the methods also revealed the inverse relationship between the flavonols and the $\mathrm{N}$ content, being the lowest in the sprayed plants, this relationship was also indicated in the studies of Stewart et al. (2001) and Fallovo et al. (2011).

Non-enzymatic antioxidants, such as polyphenols including flavonoids, come into play to mitigate the adverse effects of stress on plant. Although specific effects were not found significant in the current study, it was revealed that flavonols respond to method of the application. Since polyphenols are accumulated on the epidermal tissue of the leaves covering chlorophyll molecules from above, foliar spraying with epibrassinolide might have stimulated the synthesis of flavonols (Brunetti et al. 2013) with an ease of infuse on the surface or protected the integrity of the chloroplast and hence the flavonols in them. It was shown that chloroplasts have flavonoids, presenting an additional defense line against reactive oxygen species produced under stressful conditions (Triantaphylidés et al. 2008).

\section{Conclusions}

Studies on brassinosteroids mostly involve its effects on growth and development, and stress responses, specifically to abiotic factors. the physiological response of the tomato plant differs with the application method that EBL was given to plants. Results showed that chlorophyll contents were responsive to the EBL concentrations and the method. An inverse relationship was found between flavonols and nitrogen balance index depending on the application method. The findings of the study illustrate that possible effects of 24-epibrassinolide might be concentration-dependent and how it is administered to the plants should be taken into consideration in both scientific studies and agronomic use.

\section{Acknowledgements}

This study was financially supported by TUBITAK with 1190660 Project number

\section{References}

Agati G, Tuccio L, Kusznierewicz B, Chmiel T, Boratoszek A, Kowalski A, Grzegorzeska M, Kosson R \& Koniszewski S (2016). Nondestructive optical sensing of flavonols and chlorophyll in white head cabbage (Brassica oleracea L. var. capitata subvar. alba) grown under different nitrogen regimes. Journal of Agriculture and Food Chemistry 64: 85-94. https://doi.org/10.1021/acs.jafc.5b04962

Ali S S, Gunupuru L R, Kumar G, Khan S M, Scofield S, Nicholson P \& Doohan F M (2014). Plant disease resistance is augmented in uzu barley lines modified in the brassinosteroid receptor BRI1. BMC Plant Biology 14: 227. https://doi.org/10.1186/s12870-014-0227-1

Ali S S, Kumar, G S, Khan M \& Doohan F M (2013). Brassinosteroid enhances resistance to fusarium diseases of barley. Phytopathology 103: 1260-1267. http://dx.doi.org/10.1094 / PHYTO-05-13-0111-R

Bibi N, Ahmed I M, Fan K, Dawood M, Li F, Yuan S \& Wang X (2017). Role of brassinosteroids in alleviating toxin-induce stress of Verticillium dahlia on cotton callus growth. Environmental Science and Pollution Research 24: 12281-12292. DOI: 10.1007/s11356-0178738-6

Brunetti C, Ferdinando M D, Fini A, Pollastri S \& Tattini M (2013). Flavonoids as antioxidants and developmental regulators: Relative significance in plants and humans. International Journal of Molecular Sciences 14(2): 3540-3555. https://doi.org/10.3390/ijms 14023540

Cartelat A, Cerovic Z G, Goulas Y S, Meyer C, Lelarge J L, Prioul A, Barbottin M, Jeuffroy H, Gate P, Agati G \& Moya I (2005). Optically assessed contents of leaf polyphenolics and chlorophyll as indicators of nitrogen deficiency in wheat (Triticum aestivum L.). Field Crops Research 91(1): 35-49. DOI: 10.1016/j.fcr.2004.05.002

Ding J, Shi K \& Zhou Y H (2009). Effects of root and foliar applications of 24-epibrassinolide on fusarium wilt and antioxidant metabolism in cucumber roots. HortScience 44(5): 1340-1345. https://doi.org/10.21273/HORTSCI.44.5.1340

Dong T, Shang J, Chen J M, Liu J, Qian B, Ma B, Morrison M J, Zhang C, Liu Y, Shi Y, Pan H \& Zhou G (2019). Assessment of Portable Chlorophyll Meters for Measuring Crop Leaf Chlorophyll Concentration. Remote Sensing 11(22): 2706. https://doi.org/10.3390/rs11222706

Fallovo C, Schreiner M, Schwarz D, Colla G \& Krumbein A (2011). Phytochemical changes induced by different nitrogen supply forms and radiation levels in two leafy Brassica species. Journal of Agriculture and Food Chemistry 59: 4198-4207. DOI: 10.1021/jf1048904

Fariduddin Q, Khalil R R, Mir B A, Yusuf M \& Ahmad A (2013). 24-Epibrassinolide regulates photosynthesis, antioxidant enzyme activities and proline content of Cucumis sativus under salt and/or copper stress. Environmental Monitoring and Assessment 185: 7845-7856. dx.doi.org/10.1021/jf1048904

Gine A, López-Gómez M, Vela M D, Ornat C, Talavera M, Verdejo-Lucas S \& Sorribas F J (2014). Thermal requirements and population dynamics of rootknot nematodes on cucumber and yield losses under protected cultivation. Plant Pathology 63: 1446-1453. https://doi.org/10.1111/ppa.12217

Gözel Ç (2021). Effects of 24-epibrassinolide on root-knot nematode, Meloidogyne incognita (Kofoid \& White, 1919) Chitwood, 1949 (Tylenchida: Meloidogynidae) in tomatoes. Turkish Journal of Entomology 45(1): 13-22. http://dx.doi.org/10.16970/entoted.808416

Jagodič A, Ipavec N, Trdan S \& Laznik Ž (2017). Attraction behaviours: are synthetic volatiles, typically emitted by insect-damaged Brassica nigra roots, navigation signals for entomopathogenic nematodes (Steinernema and Heterorhabditis)? BioControl 62: 515-524. https://doi.org/10.1007/s10526-017-9796-x 
Jan S, Alyemeni M N, Wijaya L, Alam P, Siddique K H \& Ahmad P (2018). Interactive effect of 24-epibrassinolide and silicon alleviates cadmium stress via the modulation of antioxidant defense and glyoxalase systems and macronutrient content in Pisum sativum L. seedlings. BMC Plant Biology 18(1): 146. https://doi.org/10.1186/s12870-018-1359-5

Jasrotia S \& Ohri P (2014). In vitro effect of 24-epibrassinolide on antioxidative enzymes of tomato plants during Meloidogyne incognita infection. Journal of Environmental Research and Development 9(1): 188-191

Jasrotia S \& Ohri P (2017). 24-epibrassinolide reduces stress in nematode-infected tomato (Solanum lycopersicum L.) plants cultured in vitro. In Vitro Cellular \& Developmental Biology-Plant 53(6): 538-545. https://doi.org/10.1007/s11627-017-9859-9

Kaur R, Ohri P \& Bhardwaj R (2013). Effect of 28-homobrassinolide on susceptible and resistant cultivars of tomato after nematode inoculation. Plant Growth and Regulation 71(3): 199-205. https://doi.org/10.1007/s10725-013-9820-9

Kaur R, Ohri P \& Bhardwaj R (2014). Effect of 28-homobrassinolide on non-enzymatic antioxidants of tomato plant under nematode stress. Journal of Environmental Research and Development 9(2): 362-367

Llorens E, García-Agustín P \& Lapena L (2017). Advances in induced resistance by natural compounds: Towards new options for woody crop protection. Scientia Agricola 74(1): 90-100. https://doi.org/10.1590/1678-992X-2016-0012

López-Gómez M \& Verdejo-Lucas S (2017). Penetration and post-infection development of root-knot nematodes in watermelon. Spanish Journal of Agricultural Research 15(4): e1010. https://doi.org/10.5424/sjar/2017154-11189

Loveys R R \& Bird A F (1973). The influence of nematodes on photosynthesis in tomato plants. Physiological Plant Pathology 3: 525-529. https://doi.org/10.1016/0048-4059(73)90063-5

Maleita C M N, Curtis R H C, Powers S J \& Abrantes I M (2012). Inoculum levels of Meloidogyne hispanica and M. javanica affect nematode reproduction, and growth of tomato genotypes. Phytopathologia Mediterranea 51 (3): 566-576

Melakeberhan H, Webster J M \& Brooke R C (1985). Response of Phaseolus vulgaris to a single generation of Meloidogyne incognita. Nematologica 31: 191-202

Nahar K, Kyndt T, Hause B, Höfte M \& Gheysen G (2013). Brassinosteroids suppress rice defense against root-knot nematodes through antagonism with the jasmonate pathway. Molecular Plant-Microbe Interactions 26: 106-115. https://doi.org/10.1094/MPMI-05-12-0108FI

Padilla F M, Souza R, Peña-Fleitas M T, Grasso R, Gallardo M \& Thompson R B (2014). Evaluation of optical sensor measurements of canopy reflectance and of leaf flavonols and chlorophyll contents to assess crop nitrogen status of muskmelon. European Journal of Agronomy 58: 39-52. https://doi.org/10.1016/j.eja.2014.04.006

Ramírez-Godoy A, Vera-Hoyos M P, Beltran N \& Restrepo-Diaz H (2018). Application of foliar synthetic elicitors for the management of Diaphorina citri (Hemiptera: Liviidae) populations in Tahiti lime (Citrus latifolia Tanaka). HortScience 53: 1012-1020. https://doi.org/10.21273/HORTSCI13079-18

Fonseca S, Silva B R \& Lobato A K (2020). 24-epibrassinolide positively modulate leaf structures, antioxidant system and photosynthetic machinery in rice under simulated acid rain. Journal of Plant Growth Regulation 4: 1559-1576. https://doi.org/10.1007/s00344-020-10167-4

Schlemmer M, Gitelson A A, Schepers J, Ferguson R B, Peng Y, Shanahan J \& Rundquist D (2013). Remote estimation of nitrogen and chlorophyll contents in maize at leaf and canopy levels. International Journal of Applied Earth Observation and Geoinformation 25: 4754. https://doi.org/10.1016/j.jag.2013.04.003

Song L X, Xu X C, Wang F N, Wang Y, Xia X J, Shi K, Zhou Y H, Zhou J \& Yu J Q (2017). Brassinosteroids act as a positive regulator for resistance against root knot nematode involving respiratory burst oxidase homolog-dependent activation of MAPKs in tomato. Plant, Cell \& Environment 41: 1113-1125. https://doi.org/10.1111/pce.12952

Stewart A, Chapman W, Jenkins G, Graham I, Martin T \& Crozier A (2001). The effect of nitrogen and phosphorus deficiency on flavonol accumulation in plant tissues. Plant, Cell \& Environment 24: 1189-1197. https://doi.org/10.1046/j.1365-3040.2001.00768.x

Triantaphylidés C, Krischke M, Hoeberichts F A, Ksas B, Gresser G, Havaux M, Breusegem F V \& Mueller M J (2008). Singlet oxygen is the major reactive oxygen species involved in photooxidative damage to plants. Plant Physiology 148: 960-968. https://doi.org/10.1104/pp.108.125690

Xia X J, Huang L F, Zhou Y H, Mao, W H, Shi, K, Wu J X, Asami T, Chen Z \& Yu J Q (2009). Brassinosteroids promote photosynthesis and growth by enhancing activation of Rubisco and expression of photosynthetic genes in Cucumis sativus L. Planta 230 : 1185. https://doi.org/10.1007/s00425-009-1016-1

Voglar G E, Mrak T, Križman M, Jagodič A, Trdan S \& Laznik Ž (2019). Effect of contaminated soil on multitrophic interactions in a terrestrial system. Plant and Soil 435: 337-351. DOI:10.1007/s11104-018-03903-z

Yang P, Nawaz M A, Li F, Bai L \& Li J (2019). Brassinosteroids regulate antioxidant system and protect chloroplast ultrastructure of autotoxicity-stressed cucumber (Cucumis sativus L.) seedlings. Agronomy 9: 1-15. https://doi.org/10.3390/agronomy9050265

Zhang D W, Deng X G, Fu F Q \& Lin H H (2015). Induction of plant virus defense response by brassinosteroids and brassinosteroid signaling in Arabidopsis thaliana. Planta 241: 875-885. DOI: 10.1007/s00425-014-2218-8

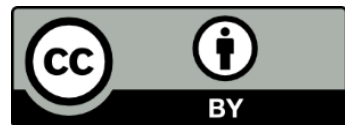

(C) 2022 by the author(s). Published by Ankara University, Faculty of Agriculture, Ankara, Turkey. This is an Open Access article distributed under the terms and conditions of the Creative Commons Attribution (CC BY) license (http://creativecommons.org/licenses/by/4.0/), which permits unrestricted use, distribution, and reproduction in any medium, provided the original work is properly cited. 